\title{
ILIAC SKELETAL CROSS TRACTION
}

\author{
A Method of Treatment of " Oyster-Shell " Pelvis \\ Guy Almond and Eric Vernon, Douglas, Isle of Man
}

From the Noble's Hospital, Isle of Man

Skeletal traction through the iliac crests has previously been used in the treatment of sacral bed-sores (Blockey 1953) and spondylolisthesis. In these cases a simple forward lift of the pelvis is all that is necessary. If the traction be taken across to the opposite side compression of the pelvis can be obtained, and if the obliquity be varied in an upward or downward direction some vertical control can also be obtained.

In cases of fracture-dislocation of the pelvis we have found difficulty in applying a hip spica in the lateral position as recommended by Watson-Jones (1943), particularly in the presence of visceral damage. The ordinary sling method is on the whole effective.

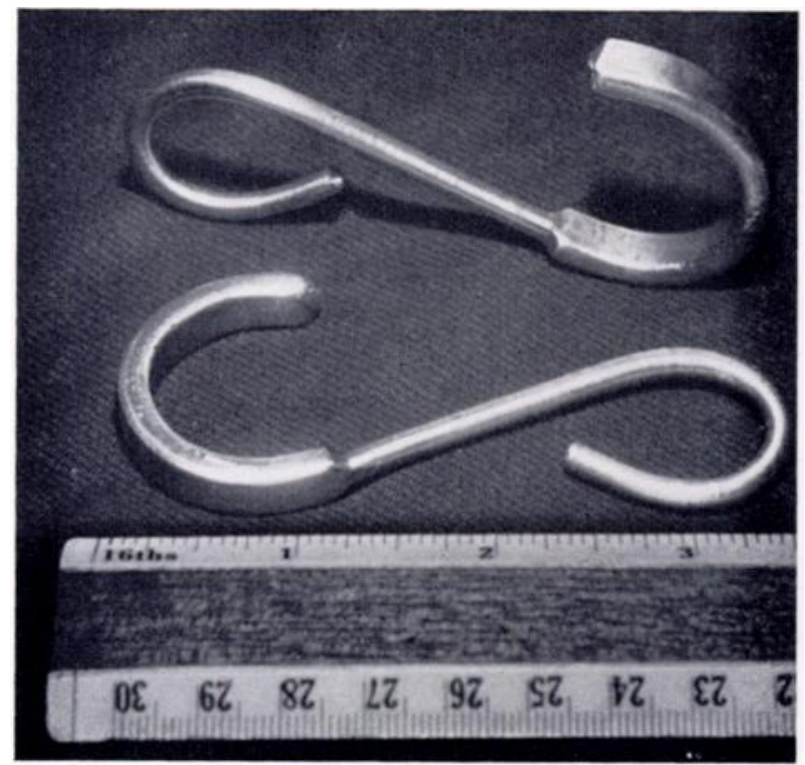

FIG. 1

The hooks: note the rectangular cross-section.

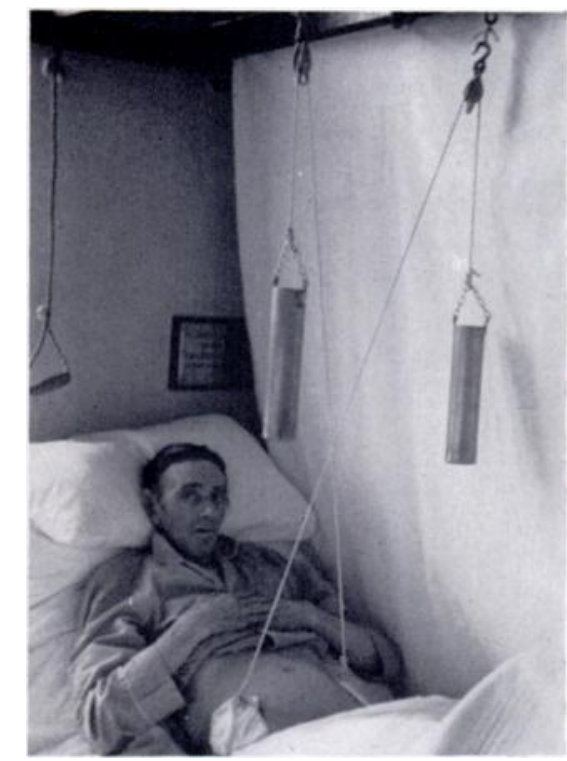

FIG. 2

The patient during treatment.

A method of skeletal compression using pins in the iliac crests and in the femur joined by turnbuckles has been described (Johnson 1957). This appears cumbersome and complicated. Wiring the symphysis has been done, but for many reasons-cutting out, sepsis, breakage of wires-is not popular.

The following technique is simple and appears to work. It is, we think, particularly applicable in the presence of other injuries.

Stainless steel hooks made flat in cross-section (to avoid cutting out) (Fig. 1) are inserted under local anaesthesia from without inwards just behind the anterior superior iliac spines. the oblong slit in the bone being made by placing two drill holes close together and breaking down the intervening bridge of bone. 


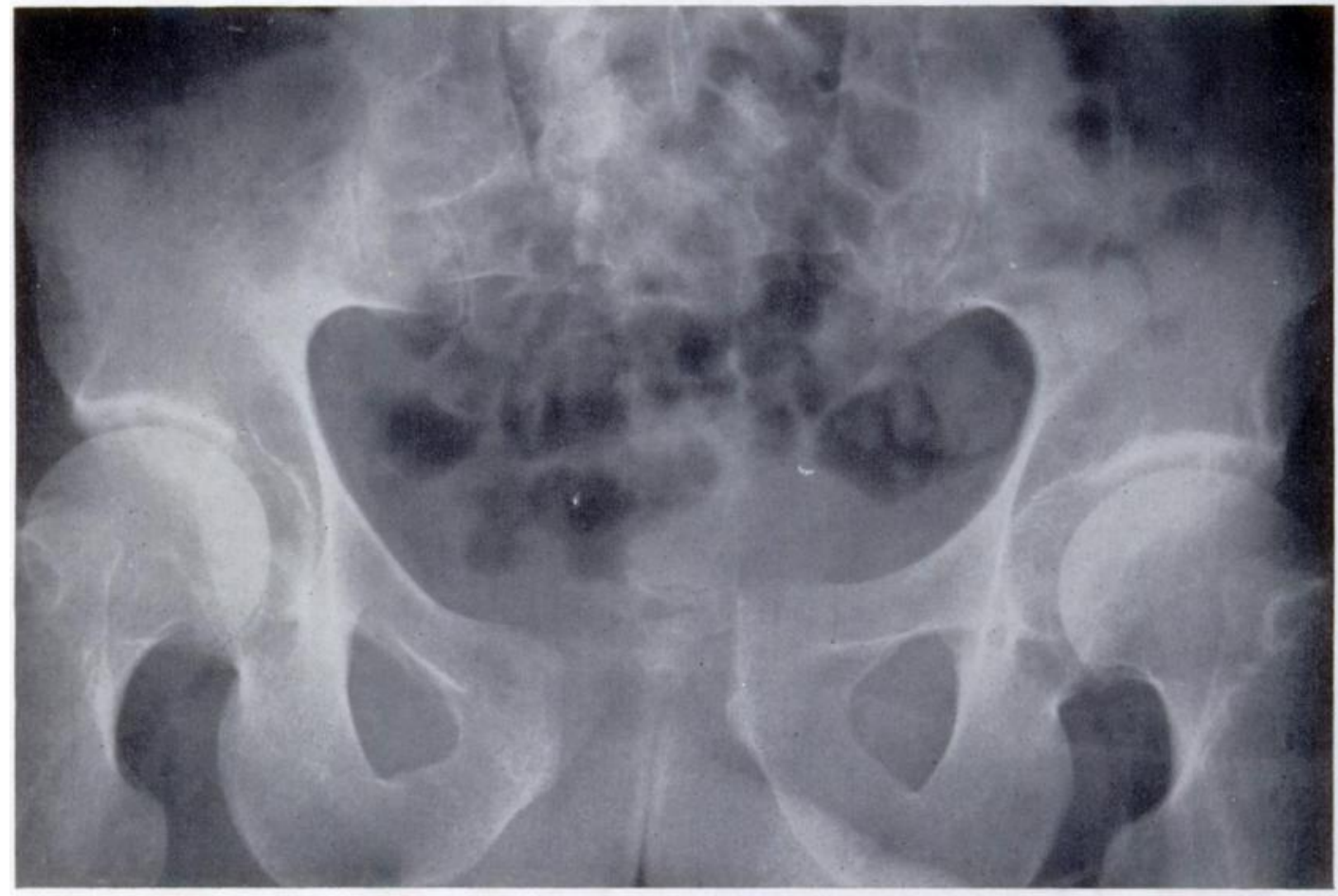

Fig. 3

The injury before treatment.

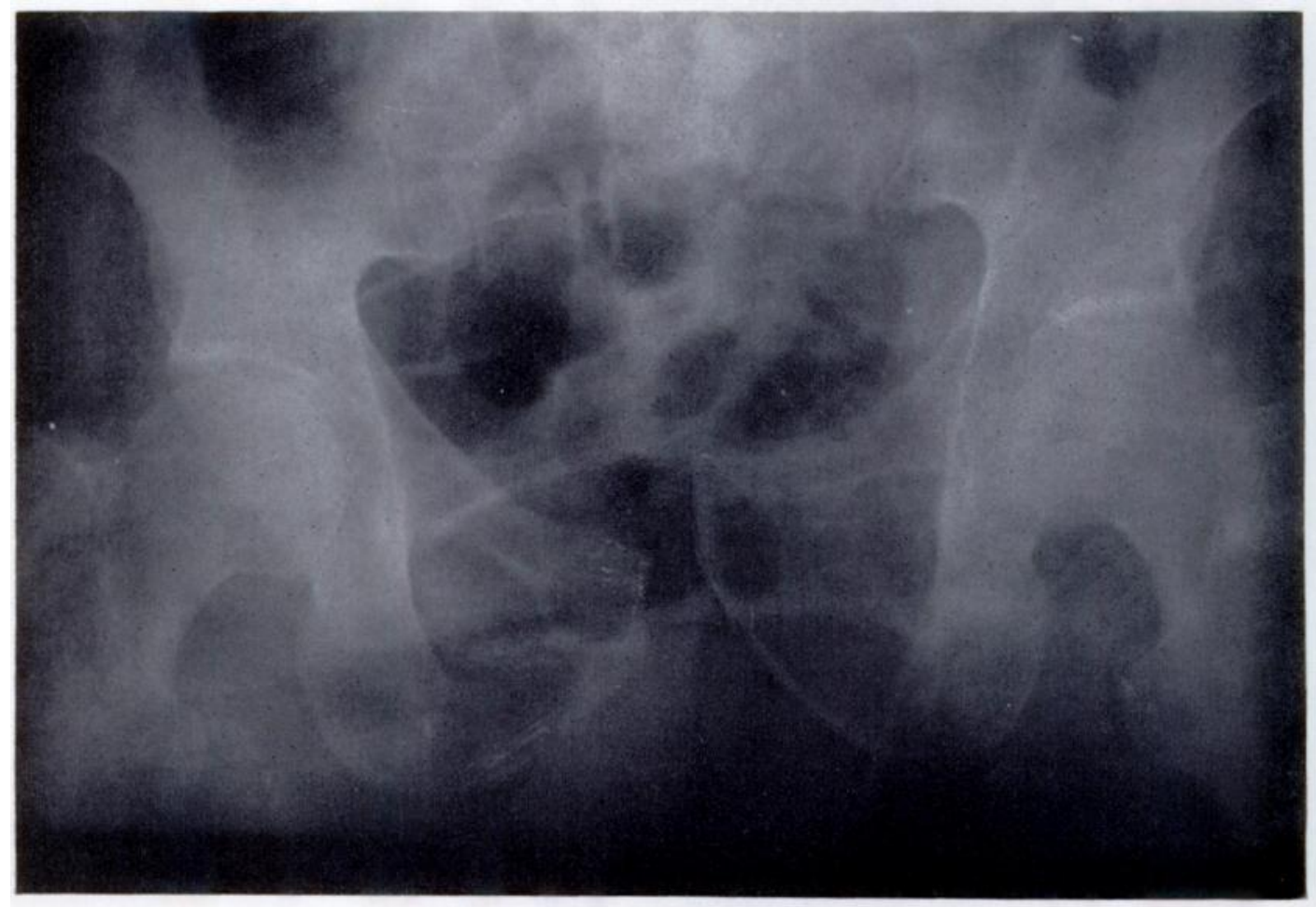

FIG. 4

After application of hip spica in lateral recumbency.

THE JOURNAL OF BONE AND JOINT SURGERY 


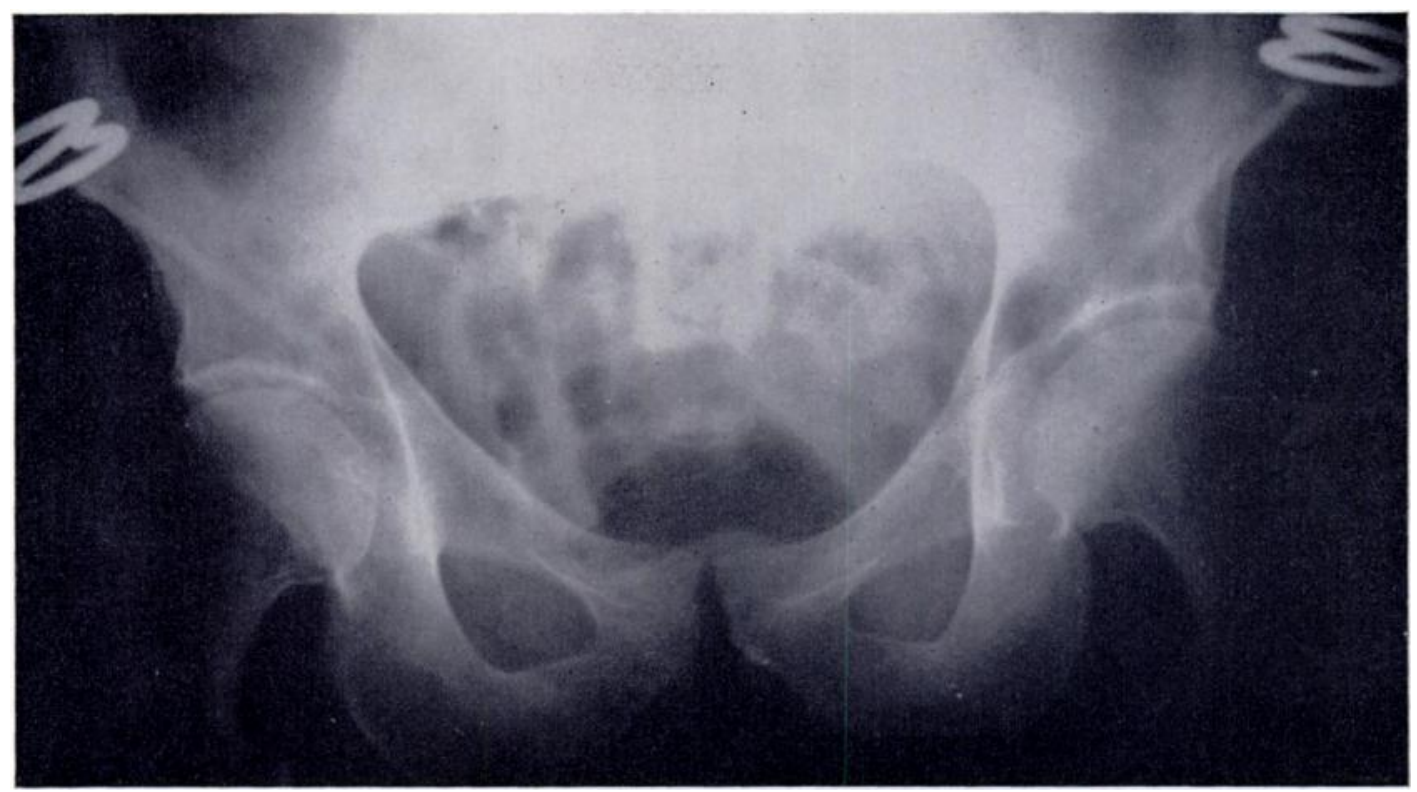

FIG. 5

After the adoption of skeletal cross traction.

In the case of the patient illustrated in Figures 2 to 5 (a slight man) eight pounds of traction on each cord was sufficient to obtain reduction and maintain apposition of the symphysis for eight weeks. This was followed by three weeks non-weight-bearing exercises and walking with crutches at twelve weeks.

If there is much upward displacement traction on the appropriate leg can be combined with the crossed iliac traction-as was done in the case shown-twelve pounds skin traction being applied to the left leg.

The original hooks were made by the engineer at the Noble's Hospital, to whom our thanks are due. They are now being made by Messrs Zimmer Orthopaedic Ltd.

\section{REFERENCES}

Blockey, N. J. (1953): Iliac-crest Suspension in the Treatment of Sacral Bedsores. Lancet, ii, 21.

Holdsworth, F. W. (1948): Dislocation and Fracture-dislocation of the Pelvis. Journal of Bone and Joint Surgery, 30-B, 461.

Johnson, W. (1957): A New Method of Pelvic Fixation. Illinois Medical Journal, 112, 59.

ReED, C. R. W. (1957): Trauma to the Pelvis and Hip. Archives of Surgery, 75, 736.

Rose, T. F. (1951): Disruption of the Pelvis. Journal of Bone and Joint Surgery, 33-B, 112.

Watson-Jones, R. (1943): Fractures and Joint Injuries. Third edition, p. 378. Edinburgh: E. \& S. Livingstone Ltd. 